\title{
Article \\ Spatiotemporal Analyses of Tomato Brown Rugose Fruit Virus in Commercial Tomato Greenhouses
}

\author{
Luis Felipe González-Concha ${ }^{1}{ }^{(}$, Joaquín Guillermo Ramírez-Gil ${ }^{2}{ }^{(1)}$, Raymundo Saúl García-Estrada ${ }^{3}$, \\ Ángel Rebollar-Alviter ${ }^{4}$ (i) and Juan Manuel Tovar-Pedraza ${ }^{3, *}$ (i)
}

1 Departamento de Ciencias Naturales y Exactas, Unidad Regional Los Mochis, Universidad Autónoma de Occidente, Los Mochis 81223, Sinaloa, Mexico; lufgonzalezcon@unal.edu.co

2 Departamento de Agronomía, Facultad de Ciencias Agrarias, Universidad Nacional de Colombia, Sede Bogotá 111321, Bogotá, Colombia; jgramireg@unal.edu.co

3 Laboratorio de Fitopatología, Coordinación Regional Culiacán, Centro de Investigación en Alimentación y Desarrollo, Culiacán 80110, Sinaloa, Mexico; rsgarcia@ciad.mx

4 Centro Regional Morelia, Universidad Autónoma Chapingo, Morelia 58170, Michoacán, Mexico; rebollaralviter@gmail.com

* Correspondence: juan.tovar@ciad.mx

check for

updates

Citation: González-Concha, L.F.; Ramírez-Gil, J.G.; García-Estrada, R.S.; Rebollar-Alviter, Á.;

Tovar-Pedraza, J.M. Spatiotemporal Analyses of Tomato Brown Rugose Fruit Virus in Commercial Tomato Greenhouses. Agronomy 2021, 11, 1268. https://doi.org/10.3390/ agronomy11071268

Academic Editor: Renaud Travadon

Received: 28 April 2021

Accepted: 18 June 2021

Published: 22 June 2021

Publisher's Note: MDPI stays neutral with regard to jurisdictional claims in published maps and institutional affiliations.

Copyright: (c) 2021 by the authors. Licensee MDPI, Basel, Switzerland. This article is an open access article distributed under the terms and conditions of the Creative Commons Attribution (CC BY) license (https:/ / creativecommons.org/licenses/by/ $4.0 /)$.

\begin{abstract}
Tomato brown rugose fruit virus (ToBRFV) is an emerging pathogen affecting tomatoproduction systems in several countries, including Mexico. This situation involves challenges due to the negative impact on yield and the lack of disease-management measures. This work analyzes the spatiotemporal distribution of ToBRFV in commercial tomato greenhouses. The presence or absence of diseased plants was evaluated weekly, assigning a location in space $(x, y)$. Temporal analysis consisted of fitting the incidence to the monomolecular, logistic, log-logistic, Gompertz, exponential, Weibull, and Richard models, evaluated using the Akaike information criterion, significance, correlation, coefficient of determination, and root mean square error. Spatial analysis consisted of determining spatial aggregation using the Moran, Fisher, and Lloyd indices. In addition, spatial distribution was assessed by sequence observations, point patterns using the inverse distance index, and analysis by SADIE distance indicators. Results indicated that the logistic models (log-logistic and logistic) best described the temporal progress of ToBRFV. This disease also had slightly aggregated patterns in the initial phase, highly aggregated in the exponential phase, and uniform in the deceleration and stationary phases. This study demonstrates that the spatial and temporal dynamics of ToBRFV have important implications for the monitoring, diagnosis, management, and risk prediction of this disease.
\end{abstract}

Keywords: ToBRFV; Solanum lycopersicum; epidemiological modeling; aggregation indices; spatial patterns

\section{Introduction}

Tomato (Solanum lycopersicum L.) is a plant native to tropical America, belonging to the Solanaceae family [1]. This vegetable accounts for one of the most economically important global production systems. The main tomato-producing countries are China, the USA, India, and Turkey. Mexico ranks 10th in production and is the world's leading tomato exporter [2], mainly to the United States, with an international market share of $24.5 \%$ of the total value of exports, representing earnings of USD 2080 billion [3].

Tomato brown rugose fruit virus (ToBRFV) is a recently described Tobamovirus that is an emerging threat, affecting open-field and greenhouse tomato crops in several countries [4-6]. It is currently spreading to new tomato-production areas, including in Mexico. This situation is of concern due to the absence of management measures, as this phytosanitary problem has negatively impacted various global production regions [7].

ToBRFV is a seed-borne, but not seed-transmitted, virus in tomatoes. The mechanical transmission of ToBRFV from infected seeds to seedlings is very likely responsible for initiating new infection, and highly impacts high-intensity crop production [8]. ToBRFV, like 
other members of the Tobamovirus genus, is very stable, which allows for it to be efficiently transmitted mechanically through the various cultural practices where plants are handled and through direct plant-to-plant contact, as well as through tools and inert materials that have direct contact with infected plants [7]. In addition, its dispersal in production units through nutrient solutions and at a low frequency by the effect of bumblebee pollination was reported [5,7].

Tobamoviruses are among the most important viruses in horticulture due to the losses they can cause [9]. In this sense, studies carried out to estimate losses in tomato-crop production due to ToBRFV infection report disease incidences between 50\% and 100\% [10], and damage to $10 \%$ to $15 \%$ of the total fruits of infected plants [11]. The greatest impact on the yield, quality, and commercial value in this crop is considered to occur when severe symptoms appear in fruits such as roughness, deformation, and the presence of brown spots [6,10-12]. In the particular case of Mexico, the presence of ToBRFV was reported in the state of Michoacán affecting tomato and pepper (Capsicum annuum L.) crops [13], as well as in Baja California, affecting tomato cultivars that carry resistance genes for other Tobamoviruses [14].

Given the growing economic importance of diseases associated with viruses of the Tobamovirus genus such as ToBRFV, it is necessary to know the spatial and temporal dynamics of the diseases they cause in order to understand different epidemiological aspects [15]. Epidemiology is used as a tool to complement basic studies to provide answers from a biological and ecological point of view concerning the development, evolution, and management of diseases [16-18]. Despite this, epidemiological studies associated with the Tobamovirus genus and especially ToBRFV under commercial conditions are scarce and not very informative.

The use of epidemiological models supports the analysis of variables of phytopathological interest such as incidence and severity. These data are used to forecast and analyze disease dynamics, which are then incorporated into integrated management tools. Techniques used for the development of these analyses include temporal and spatial models [18]. Thus, epidemic modeling contributes to a broad understanding of disease dynamics in time and space, which has led to the establishment of management strategies focused on the biological, genetic, and evolutionary aspects of both the hosts and these agents [19].

Despite the importance of the effect of this pathosystem on global tomato crops, studies aimed at the characterization of epidemics as a basis for the design and implementation of integrated management strategies have not been conducted. For this reason, the objective of this study was to analyze and understand the spatiotemporal distribution of ToBRFV through mathematical modeling in five commercial tomato greenhouses, as a basis for the formulation of proposals for the management of the disease.

\section{Materials and Methods}

\subsection{Study Area and Production-System Characterization}

The study was conducted in a commercial tomato production farm during the second cycle of 2019 from July to December (weeks 28-51 of the year). During this period, five commercial greenhouses established with the TOP-2299 cultivar (Top Seeds ${ }^{\circledR}$ ) were monitored.

For the characterization of the epidemic caused by ToBRFV, five greenhouses ranging in area from 1 to 1.3 ha were selected in which different plant densities were established with different transplanting dates (Table 1). In each of the greenhouses, the plants were transplanted in $1 \mathrm{~m}$ long coconut fiber slabs distributed in $40 \mathrm{~m}$ furrows. In each furrow, 40 slabs were established that contained three planting sites, transplanting two plants per site. The distance between planting sites was $33 \mathrm{~cm}$, and the distance between rows was $1.20 \mathrm{~m}$. 
Table 1. Characteristics of commercial tomato greenhouses cv. TOP-2299 during the 2019 cycle.

\begin{tabular}{ccccc}
\hline Greenhouse & Area (ha) & Number of Plants/Greenhouse & Number of Furrows & Transplanting Date \\
\hline 1 & 1.3 & 33,600 & 140 & 15 July 2019 \\
\hline 2 & 1.0 & 26,400 & 110 & $11 \mathrm{July} 2019$ \\
\hline 3 & 1.1 & 28,800 & 120 & $10 \mathrm{July} 2019$ \\
\hline 4 & 1.15 & 30,000 & 125 & $13 \mathrm{July} 2019$ \\
\hline 5 & 1.2 & 31,200 & 130 & $20 \mathrm{July} 2019$ \\
\hline
\end{tabular}

A high-intensity production system with a 168 day cycle (24 weeks) was used. The main cultural practice carried out was the tutoring of the plants, which was carried out weekly throughout the crop cycle. Harvesting was carried out from Week 35 with an average periodicity of 2 days, while leaf removal began in Week 36 and was performed weekly until the end of the production cycle. Fertilization was conducted through a combined mixture of nutrients using the application efficiency of the irrigation system, which was carried out by means of drip-type emitters under technical and technological agricultural criteria.

\subsection{Detection of ToBRFV by RT-PCR}

Before conducting the study, samples of leaves and fruits with symptoms associated with ToBRFV infection in tomato plants were collected in each greenhouse. The virus was detected and identified through reverse transcription polymerase chain reaction (RT-PCR). Twenty-five samples from the five commercial greenhouses were processed (three symptomatic leaf samples and two fruit ones per greenhouse). Viral detection was performed with the specific ToBRFV-FMX and ToBRFV-RMX oligonucleotides, which amplify a $475 \mathrm{bp}$ fragment that encodes a region of the RdRp located in ORF1 [20].

\subsection{Design and Data Collection in the Greenhouses}

All tomato plants in each greenhouse were monitored. Each plant was considered to be a sampling unit, where the amount of disease present in the total population was evaluated, which was quantified by the incidence (number of diseased plants with respect to the total number of plants). Plant status (healthy or diseased) was determined by visual inspection of the expression of foliar symptoms (mosaics) present on leaves located in the upper third of the plant (Figure 1), characteristic of the infection caused by ToBRFV in tomato crops [6,10-12].

For temporal analysis, weekly monitoring was conducted from the first week after transplanting (Week 28) until the end of the crop cycle (24 evaluations). Additionally, for spatial analysis, the presence or absence of ToBRFV was determined in each of the plants in the five evaluated greenhouses, assigning their location in space using coordinates $(x, y)$. This evaluation was carried out from Week 40 until the end of the crop cycle for a total of 12 evaluations.

\subsection{Temporal Analysis}

Incidence data for each greenhouse were plotted against time, obtaining the area under the disease progress curve [21]. From this curve, the absolute rate $(\mathrm{dy} / \mathrm{dt})$ was determined for each evaluation period. Raw incidence data were fitted to monomolecular, logistic, Gompertz, exponential, and Richard models, which are commonly used in agricultural epidemiology [21]. Additionally, the log-logistic and Weibull models were evaluated. The log-logistic model presents a good fit in progress curves that are characterized by peaks after a finite period of growth followed by a slow decline, making this type of behavior suitable for representation with models that have a nonmonotonic failure rate [22], whereas the Weibull model represents cumulative distributions such as disease progress curves, due 
to its simplicity and flexibility in its epidemiological applications [23]. The mathematical expressions of the used models and their linearized form are reported in Table 2.

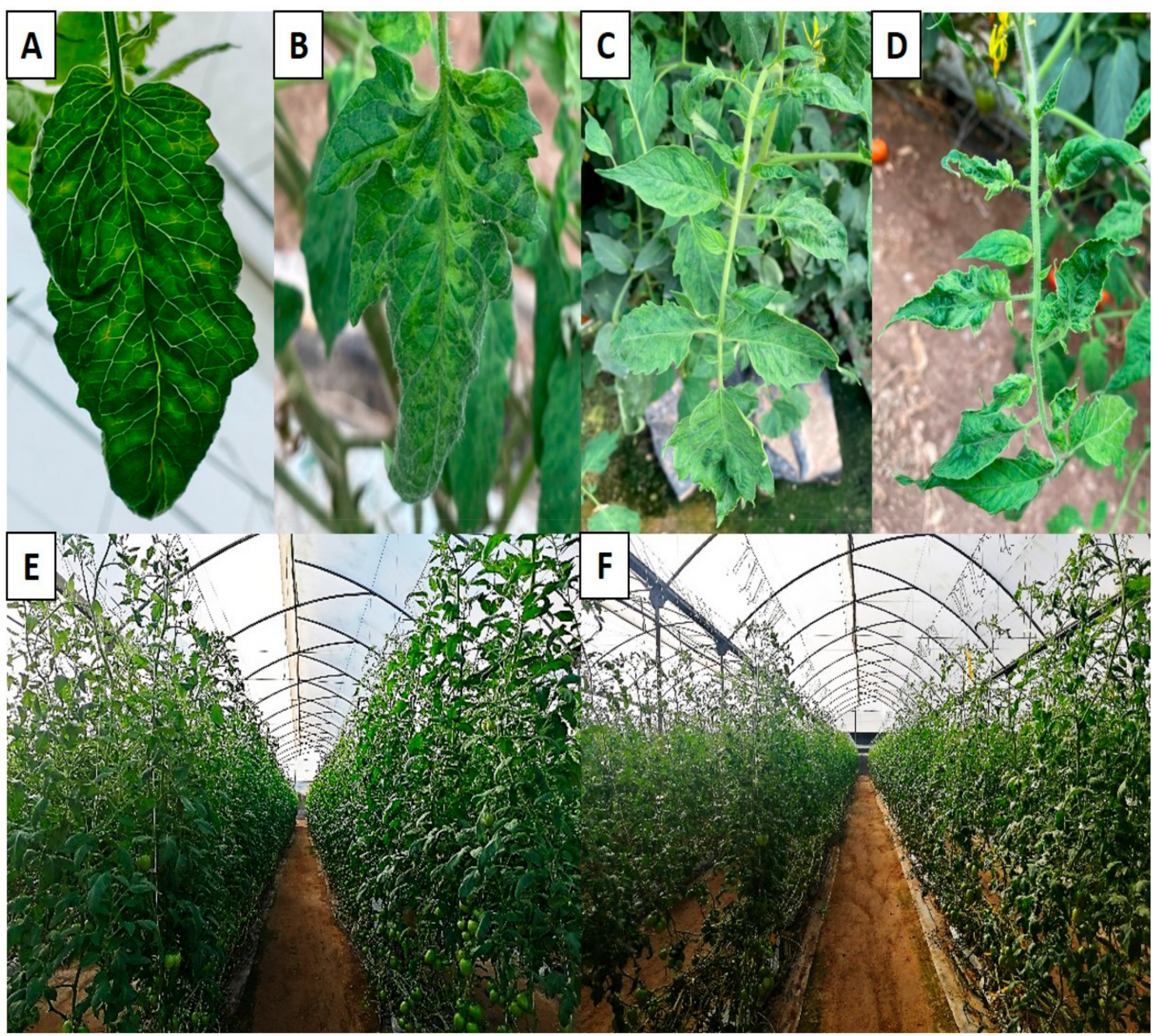

Figure 1. Foliar symptoms caused by ToBRFV in tomato plants cv. TOP-2299. (A,B) Severe mosaics on leaflets. (C,D) Deformation of leaves. (E) Low incidence of infected plants. (F) High incidence of infected plants.

Table 2. Models used to fit ToBRFV progress curves in tomato plants cv. TOP-2299 under greenhouse conditions.

\begin{tabular}{ccc}
\hline Model & Differential Form & Linearized Form \\
\hline Exponential $^{1}$ & $y(t)=r E(y)$ & $\left(\ln [\mathrm{y}]=\ln \left(\mathrm{y}_{0}\right)+\mathrm{rEt}\right)$ \\
\hline Gompertz $^{1}$ & $y(t)=r G y[-\ln (\mathrm{y})]$ & $(-\ln [-\ln \mathrm{y}]=-\ln [-\ln (\mathrm{y})]+\mathrm{rGt})$ \\
\hline Logistic $^{1}$ & $y(t)=r L y(1-y)$ & $(\ln [\mathrm{y} /(1-\mathrm{y})]=0 \ln [\mathrm{y} /(1-\mathrm{y})]+\mathrm{rLt})$ \\
\hline Monomolecular $^{1}$ & $y(t)=r M(1-y)$ & $(\ln [1 /(1-\mathrm{y})]=\ln [1 /(1-\mathrm{y})]+\mathrm{rMt})$. \\
\hline Richard $^{1}$ & $y(t)=[\mathrm{rR} /(\eta-1)] y\left(1-y^{\mathrm{\eta}-1}\right)$ & $\left(\ln \left[/\left(1 / 1-\mathrm{y}^{1-n}\right)\right]=\left(\ln \left[/\left(1 / 1-\mathrm{y}^{1-n}\right)\right]+r_{R} t\right.\right.$ \\
\hline Log-logistic $^{2}$ & $y(t)=r L y\left[1-y^{*} \ln (y)\right]$ & $(\ln [\mathrm{y} /(1-\mathrm{y})]=0 \ln [\mathrm{y} /(1-\mathrm{y})]+\mathrm{t})$ \\
\hline Weibull $^{3}$ & $y(t)=c / b(t-a / b)^{c-1} e x\left[-(t-a / b)^{c}\right]$ & $(\ln [\ln /(1 / 1-\mathrm{y})]=-c \ln (b)+c \ln (t-a)$ \\
\hline
\end{tabular}

Mathematical expressions for the model and its linearized form are based on ${ }^{1}[21] ;{ }^{2}[22] ;{ }^{3}$ [23]. $t$ : time; rC, rate parameter (units $1 /$ time, when C: E, G, L, M, and R to exponential or Gompertz, logistic, monomolecular, and Richard models, respectively); $\eta$ : parameter affected by form curve $(f(1-y)=1-y \eta-1) \mathrm{y}_{0}$, integration constant; $\mathrm{y}$ : initial intensity of disease when $\mathrm{t}: 0 ; a$ and $b$ : parameters of Weibull model; $a$ : location parameter and the earliest occurrence of the disease; $b$ : scale parameter inversely proportional to the rate of disease increase (time units); and $c$ : unitless parameter controlling the shape of the rate curve (dy/dt vs. t) and the inflection point. 
From the linearized form of the models, parameters $\beta 0$ (intercept) and $\beta 1(x)$ (slope) were determined. The fit of the models was evaluated through the estimation of statistical parameters such as a balance between complexity using the Akaike information criterion (AIC), statistical significance $(p<0.05)$ and predictive ability through the correlation coefficient $(r)$, coefficient of determination ( $r 2)$, and root mean square error (RMSE). Likewise, for all models, residuals were analyzed to guarantee assumptions of normality, independence, and constant variances of errors with a significance level of $95 \%(\alpha=0.05)$. At the same time, from the linear form of the model that best fit the incidence of ToBRFV (log-logistic), disease growth rate $(r)$ at different stages of epidemic development (initial, exponential growth, deceleration, and stationary) was determined [21].

These procedures were developed with free software R [24], utilizing our own code using functions of the mgcv [25], ModelMetrics [26], and drc [27] libraries.

\subsection{Spatial Analysis}

Intensive mapping was carried out on the basis of the position of each plant (sampling unit) in each of the evaluated greenhouses, where its location in space was determined by assigning coordinates ( $\mathrm{x}$ : planting site, $\mathrm{y}$ : furrow). With this information, spatial analyses were carried out, for which the data on the presence (1) and absence (0) of the disease were selected using values found in the last week of the four phases identified in the epidemic (initial, exponential, deceleration, and stationary) according to the growth rate of the disease (Table 3).

Table 3. Disease growth rates (r) associated with four phases of ToBRFV epidemic in commercial tomato greenhouses, determined from the log-logistic model.

\begin{tabular}{ccc}
\hline Epidemic Stage & r (Growth Rates) & Development Time (Weeks) \\
\hline Initial & $0.0001-0.0009$ & $28-41$ \\
Rapid or exponential & $>0.03$ & $41-48$ \\
Deceleration & $0.001-0.029$ & $48-50$ \\
Stationary & $<0.02$ & $50-51$ \\
\hline
\end{tabular}

$\mathrm{r}=$ value calculated in each phase of the epidemic from the linearized form of log-logistic model.

In the first part of the analysis, aggregation and spatial dependence were estimated using Moran's index (MI), which can be used for nominal variables (healthy (0) and diseased (1)), where values close to 0 , less than -1 , and close to 1 indicate a random, uniform, and aggregated spatial pattern, respectively [28]. As a complement to the previous test, the Fisher [29], and Lloyd [30] indices were determined, where values $<1,=1$, and $>1$ for both indicate a uniform, random, and aggregated pattern, respectively. On the basis of this information and following the classification criteria [31], spatial aggregation was divided into four descriptive classifiers according to the numerical value of Moran's index: random (0), slightly aggregated (0.01-0.6), highly aggregated (0.61-1), and uniform $(<-1)$. Additionally, to know the spatial distribution of the disease in the early stages, we calculated the aggregation index in Week 35, just before harvest began, and the cultural management practices that probably influenced the mechanical transmission. Likewise, during this week, the first cases of visual expression of the disease were presented.

Subsequently, and given the origin of the response variable (nominal-dichotomous), point and area patterns were used as tools for analyzing and visualizing the spatial distribution. In this sense, three strategies were used. The first consisted of sequence observations of the presence and absence in space as a function of time. For the second, a point pattern was used, where the "point" was a function of the values of the coordinates $(x, y)$, and the "mark" was a function of the value of the presence (1) or absence (0) of the disease for each time of the epidemic, from which interpolation was performed using the inverse distance weighted (IDW) method [32]. The third strategy entailed spatial analysis by distance indicators using SADIE, which calculates different indices and probabilities as a function of the most regular distance for the observed spatial pattern and a specified number of 
random permutations of this pattern. This index expresses the probability that a certain phenomenon occurs in space [33-35].

In this work, we opted to use the statistical parameters in the SADIE analysis of absolute index, index rank, and its graphical representation based on the index called "red-blue" plots, which detect the clusters of interest, and facilitate a complete definition of the size and dimension of the cluster [36]. The biological and epidemiological interpretation of these parameters is associated with the fact that, when the values of the index rank are greater than 1.5, they indicate the aggregation of the evaluated phenomenon, indicating areas where the inoculum source is located (red circles), while values less than 1.5 indicate the aggregation of the opposite phenomenon; in this case, they show healthy plants (blue circles), representing areas that can potentially become infected. On the other hand, values between -1.5 and 1.5 indicate areas of interception of the two phenomena.

The size of the circles (red and blue) in the absolute index indicates the size, intensity, and dimension of the phenomenon (healthy and infected areas). All analyses performed in this work were developed with the free software R using the Geo R [37], Epiphy [38], and akima [39] libraries.

\section{Results}

\subsection{Detection of ToBRFV by RT-PCR}

All tissue samples (leaves and fruits) of tomato cv. TOP-2299 from the five greenhouses (1 to 5) tested positive for ToBRFV because the expected $475 \mathrm{bp}$ fragment was amplified, confirming the presence of the virus in the study area.

\subsection{Temporal Analysis of the Tomato Epidemic Caused by ToBRFV}

All epidemics represented by the progress curves obtained in the five greenhouses had a sigmoidal shape, characteristic of logistic models (log-logistic and logistic), which described the dynamics of the behavior of the disease during the productive cycle of the crop (Figure 2A). These types of curves were characterized by presenting an initial phase of the epidemic, where a slow increase in incidence was observed during weeks 28-41, followed by an exponential or rapid-growth phase of the disease between weeks 41-48, and a deceleration and stationary phase where incidence values slowly approached $100 \%$ during weeks 48-51 (Figure 2A and Table 3).

In general, a symmetric absolute rate curve was presented in all greenhouses, with primary infections observed during weeks 35-37 (Figure 2B and Table 3). In this period, there was a low number of infected plants, which showed mosaic symptoms, vein clearing, anatomical abnormalities, wrinkling, and deformation of leaves. The absolute rate progress curve was characterized by a progressive increase in the disease, which occurred in weeks 41-48 (Figure 2B and Table 3), where the viral spread rate within the greenhouses increased; as the amount of disease (incidence) increased, the absolute growth rate increased due to the continuous production of inoculum and the development of secondary infections. The highest ToBRFV infection rate occurred when the incidence of the virus reached $50 \%$ for all evaluated greenhouses (Figure 2B and Table 3). Lastly, the absolute rate decreased in the last four weeks of evaluation, since 100\% diseased plants (crop-load capacity) were reached in almost all cases at the end of the production cycle (Figure 2B and Table 3).

The estimation of the statistical parameters associated with the balance between low complexity (AIC), significance ( $p$ value), and predictive ability ( $r, r 2$, and RMSE) indicated that the log-logistic, logistic, Gompertz, and Weibull models best fit the disease-progress data in the five evaluated greenhouses (Figure 2C), with the logistic models (log-logistic and logistic) being the ones that had the best fit to the temporal dynamics of the disease (Table 4). In this sense, the adjusted $r$ and $r 2$ values for the logistic models (log-logistic and logistic) presented values of $\geq 0.89$ and $>79 \%$, respectively. In addition, these models had the lowest values of AIC $(<146.00)$ and RSME $(<0.104)$ (Table 4). 

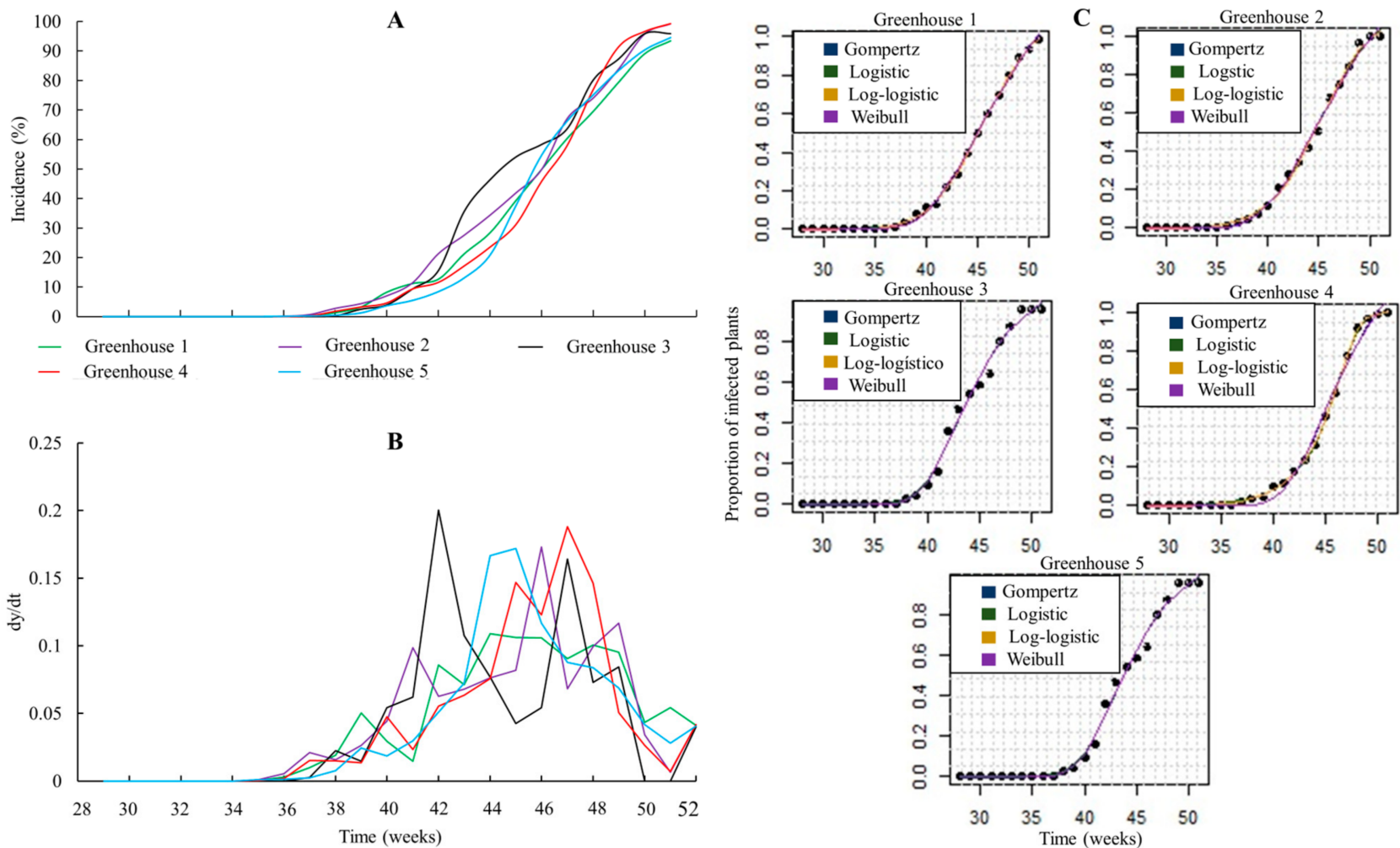

Figure 2. Progress curves and mathematical model adjustments associated with Tomato brown rugose fruit virus (ToBRFV) in five commercial tomato greenhouses. (A) Disease progress curves. (B) Absolute incidence rate in each evaluated period. (C): Disease progress curves adjusted for four epidemiological models.

Table 4. Estimation of statistical parameters for the selection of the best-fit model associated with the temporal dynamics of ToBRFV in commercial tomato greenhouses.

\begin{tabular}{|c|c|c|c|c|c|c|c|c|}
\hline Greenhouse & Model & $\beta_{0}$ & $\beta_{1}$ & Correlation (r) & Adjusted $\mathbf{r}^{2}$ & Significance & RMSE & AIC \\
\hline \multirow{7}{*}{1} & Log-logistic & -0.041 & 0.044 & 0.94 & 93.45 & $* * *$ & 0.092 & 101.449 \\
\hline & Logistic & -0.28 & 0.047 & 0.91 & 83.79 & $* * *$ & 0.095 & 110.251 \\
\hline & Gompertz & -0.60 & 0.27 & 0.84 & 70.55 & $* *$ & 0.098 & 115.415 \\
\hline & Weibull & -0.40 & 0.31 & 0.72 & 52.43 & * & 0.102 & 120.857 \\
\hline & Richard & -0.28 & 0.34 & 0.65 & 50.35 & ns & 0.205 & 230.521 \\
\hline & Exponential & -0.45 & 0.15 & 0.62 & 48.32 & ns & 0.325 & 345.145 \\
\hline & Monomolecular & -0.38 & 0.23 & 0.58 & 46.3 & ns & 0.544 & 456.324 \\
\hline \multirow{7}{*}{2} & Log-logistic & -0.03 & 0.045 & 0.93 & 92.19 & $* * *$ & 0.098 & 105.709 \\
\hline & Logistic & -0.29 & 0.050 & 0.92 & 85.45 & $* * *$ & 0.103 & 110.257 \\
\hline & Gompertz & -0.63 & 0.287 & 0.85 & 72.56 & $* *$ & 0.110 & 130.587 \\
\hline & Weibull & -0.42 & 0.331 & 0.73 & 54.41 & $*$ & 0.115 & 160.387 \\
\hline & Richard & -0.12 & 0.45 & 0.62 & 52.4 & ns & 0.258 & 230.456 \\
\hline & Exponential & -0.10 & 0.38 & 0.58 & 46.8 & ns & 0.345 & 240.132 \\
\hline & Monomolecular & -0.23 & 0.18 & 0.51 & 42.52 & ns & 0.500 & 300.265 \\
\hline
\end{tabular}


Table 4. Cont.

\begin{tabular}{|c|c|c|c|c|c|c|c|c|}
\hline Greenhouse & Model & $\beta_{0}$ & $\beta_{1}$ & Correlation (r) & Adjusted $\mathrm{r}^{2}$ & Significance & RMSE & AIC \\
\hline \multirow{7}{*}{3} & Log-logistic & -0.01 & 0.041 & 0.94 & 90.21 & $* * *$ & 0.096 & 108.413 \\
\hline & Logistic & -0.29 & 0.051 & 0.92 & 85.77 & $* * *$ & 0.100 & 112.321 \\
\hline & Gompertz & -0.64 & 0.29 & 0.85 & 73.39 & $* *$ & 0.105 & 130.521 \\
\hline & Weibull & -0.44 & 0.341 & 0.74 & 55.34 & * & 0.110 & 134.442 \\
\hline & Richard & -0.099 & 0.02 & 0.65 & 58.45 & ns & 0.215 & 200.312 \\
\hline & Exponential & -0.09 & 0.021 & 0.57 & 51.20 & ns & 0.325 & 325.145 \\
\hline & Monomolecular & -0.091 & 0.022 & 0.49 & 47.25 & ns & 0.425 & 455.235 \\
\hline \multirow{7}{*}{4} & Log-logistic & -0.04 & 0.045 & 0.92 & 89.13 & $* * *$ & 0.095 & 122.135 \\
\hline & Logistic & -0.30 & 0.049 & 0.89 & 79.60 & $* * *$ & 0.097 & 129.369 \\
\hline & Gompertz & -0.62 & 0.279 & 0.81 & 66.18 & $* *$ & 0.098 & 135.422 \\
\hline & Weibull & -0.42 & 0.318 & 0.69 & 48.51 & * & 0.100 & 145.258 \\
\hline & Richard & -0.088 & 0.021 & 0.62 & 57.21 & ns & 0.185 & 256.423 \\
\hline & Exponential & -0.065 & 0.054 & 0.61 & 51.42 & ns & 0.155 & 312.654 \\
\hline & Monomolecular & -0.085 & 0.035 & 0.57 & 48.25 & ns & 0.215 & 358.321 \\
\hline \multirow{7}{*}{5} & Log-logistic & -0.02 & 0.043 & 0.91 & 88.88 & $* * *$ & 0.088 & 132.403 \\
\hline & Logistic & -0.30 & 0.048 & 0.89 & 79.68 & $* * *$ & 0.095 & 145.249 \\
\hline & Gompertz & -0.61 & 0.27 & 0.81 & 66.28 & $* *$ & 0.098 & 150.357 \\
\hline & Weibull & -0.41 & 0312 & 0.69 & 48.16 & * & 0.100 & 155.327 \\
\hline & Richard & -0.11 & 0.002 & 0.58 & 53.21 & ns & 0.125 & 300.123 \\
\hline & Exponential & -0.17 & 0.002 & 0.53 & 47.25 & ns & 0.175 & 325.461 \\
\hline & Monomolecular & 0.017 & 0.021 & 0.49 & 42.35 & ns & 0.953 & 395.48 \\
\hline
\end{tabular}

$\beta_{0}$ : intercept of models; $\beta_{1}$ : slope of the models. RSME: root mean square error. AIC: Akaike information criterion. ${ }^{* *}: p<0.001 ;{ }^{* *} p<0.01$; ${ }^{*} p<0.05$, ns: not significant.

Spatial and temporal analysis of the epidemic in Greenhouse 5 was the one that best represented the behavior of the disease, given that it presented the least deviation associated with the mean values of ToBRFV incidence, with respect to the overall mean evaluated in the five greenhouses, thus characterizing the dynamics of the epidemic in a homogeneous manner in time and space. On the basis of this criterion, the temporal progress of the epidemic in Greenhouse 5 showed the best fit with respect to the four selected models in both their integral and linearized forms (log-logistic, logistic, Gompertz, and Weibull), with the log-logistic model being the one that best described the temporal dynamics of the epidemic (Figure 3). From the linearized form of this model, it was possible to identify that the highest rate of disease development was obtained in the growth or exponential phase, followed by the deceleration, stationary, and initial phases (Table 3).

\subsection{Spatial Analysis of Tomato Epidemic Caused by ToBRFV}

The autocorrelation and spatial-dependence results for the last week of each phase of the epidemic indicated that the spatial patterns were similar in each of the evaluated greenhouses (Table 5). MI values indicated that, in the preinitial and initial phase of the epidemic, there was a random and slightly aggregated pattern with null and moderate spatial dependence; for the rapid-growth phase, there was a highly aggregated pattern with high spatial dependence; and for the deceleration and stationary phases, there was a uniform distribution pattern. The results of disease distribution in space were corroborated by calculating the FI and YI values for each phase of the epidemic (Table 5). 

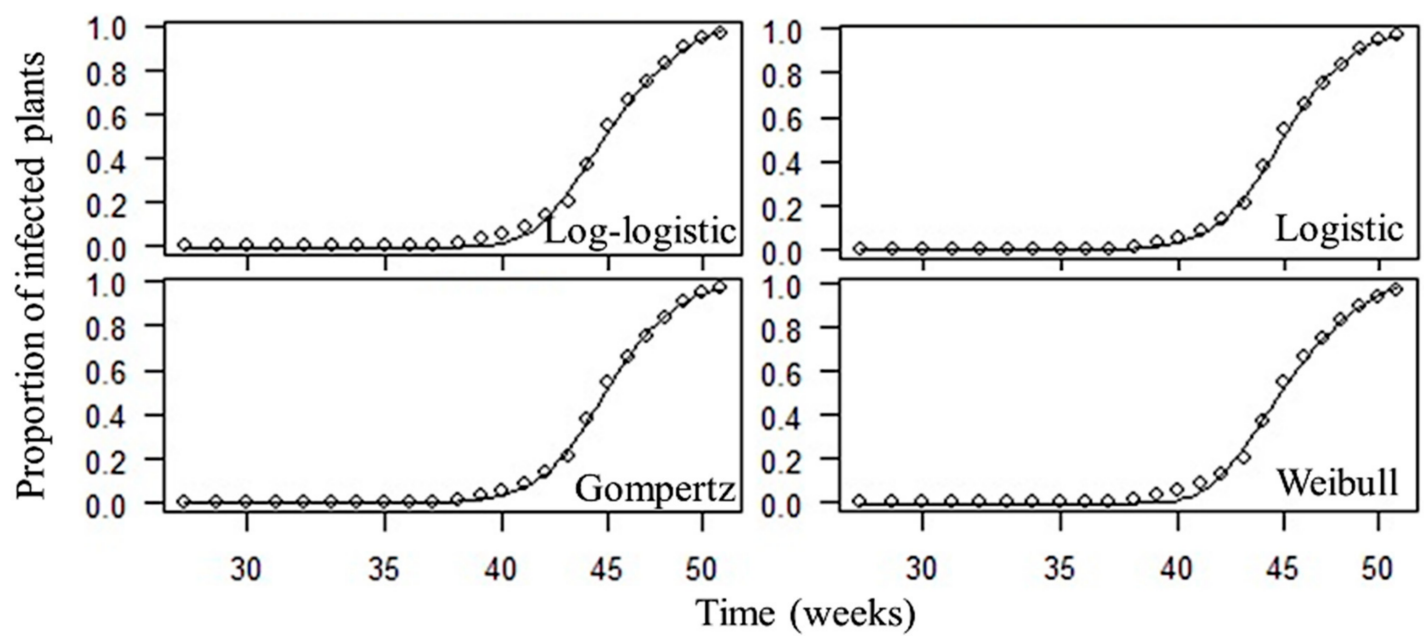

Figure 3. Graphic representation of fit of best four models associated with the temporal progress of ToBRFV in commercial tomato greenhouses. Disease progress curves adjusted for the four models with the best computational performance, significance, and prediction capacity.

Table 5. Statistical parameters associated with spatial-dependence analysis of ToBRFV in commercial tomato greenhouses.

\begin{tabular}{|c|c|c|c|c|c|c|}
\hline Greenhouse & $\begin{array}{l}\text { Epidemic } \\
\text { Stage }\end{array}$ & $\begin{array}{c}\text { Moran } \\
\text { Index }\end{array}$ & $p$ Value $^{1}$ & Fisher Index & Lloyd Index & Spatial Pattern $^{2}$ \\
\hline \multirow{5}{*}{1} & Preinitial $^{3}$ & 0.01 & $* * *$ & 1.01 & 1.00 & Random \\
\hline & Initial & 0.59 & $*$ & 1.21 & 1.1 & Slightly aggregated \\
\hline & Exponential & 0.95 & $* * *$ & 2.32 & 1.9 & Highly aggregated \\
\hline & Deceleration & -1.38 & ns & 0.48 & 0.35 & Uniform \\
\hline & Stationary & -5.31 & ns & 0.31 & 0.24 & Uniform \\
\hline \multirow{5}{*}{2} & Preinitial $^{3}$ & 0.08 & $* * *$ & 1.02 & 1.01 & Random \\
\hline & Initial & 0.61 & $*$ & 1.22 & 1.09 & Slightly aggregated \\
\hline & Exponential & 0.96 & $* * *$ & 2.45 & 1.99 & Highly aggregated \\
\hline & Deceleration & -3.49 & ns & 0.51 & 0.42 & Uniform \\
\hline & Stationary & -4.99 & ns & 0.30 & 0.27 & Uniform \\
\hline \multirow{5}{*}{3} & Preinitial $^{3}$ & 0.04 & $* * *$ & 1.00 & 1.01 & Random \\
\hline & Initial & 0.42 & $*$ & 1.21 & 1.31 & Slightly aggregated \\
\hline & Exponential & 0.95 & ** & 2.49 & 2.2 & Highly aggregated \\
\hline & Deceleration & -4.32 & ns & 0.49 & 0.39 & Uniform \\
\hline & Stationary & -4.98 & ns & 0.28 & 0.24 & Uniform \\
\hline \multirow{5}{*}{4} & Preinitial $^{3}$ & 0.05 & $* *$ & 1.02 & 1.01 & Random \\
\hline & Initial & 0.53 & $*$ & 1.41 & 1.21 & Slightly aggregated \\
\hline & Exponential & 0.97 & $* * *$ & 2.49 & 2.23 & Highly aggregated \\
\hline & Deceleration & -3.21 & ns & 0.49 & 0.41 & Uniform \\
\hline & Stationary & -5.39 & ns & 0.31 & 0.25 & Uniform \\
\hline \multirow{5}{*}{5} & Preinitial $^{3}$ & 0.06 & $* *$ & 1.00 & 1.00 & Random \\
\hline & Initial & 0.58 & * & 1.42 & 1.19 & Slightly aggregated \\
\hline & Exponential & 0.96 & $* * *$ & 5.00 & 2.13 & Highly aggregated \\
\hline & Deceleration & -2.99 & ns & 0.48 & 0.38 & Uniform \\
\hline & Stationary & -5.12 & ns & 0.32 & 0.21 & Uniform \\
\hline
\end{tabular}

${ }^{* * *}: p<0.001 ;{ }^{* *} p<0.01 ; * p<0.05$, ns: not significant. ${ }^{1}$ Significance based on Moran index (MC). ${ }^{2}$ Categorization based on classification principles applied to Moran index (MI) [31]. ${ }^{3}$ Early stages (Week 35). 
As in the case of temporal analysis, Greenhouse 5 presented the best fit in spatial analysis. From this and on the basis of the first evaluated visualization strategy, the sequence observations of the presence (1) and absence (0) of the disease in space as a function of time allowed for identifying that the initial phase of the epidemic ( $t 1$, Week 41) exhibited a slightly aggregated spatial pattern, represented by foci of different sizes, randomly distributed and in an aggregate manner in the center of the greenhouse. On the other hand, the rapid-growth phase ( $\mathrm{t} 2$, Week 48) presented a highly aggregated pattern, where the initial foci expanded, and new foci of infection appeared; in the deceleration ( $\mathrm{t} 3$, Week 50) and stationary ( 4 , Week 51) phases, uniform spatial patterns were observed as a consequence of the coalescence of primary and secondary foci (Figure 4A).
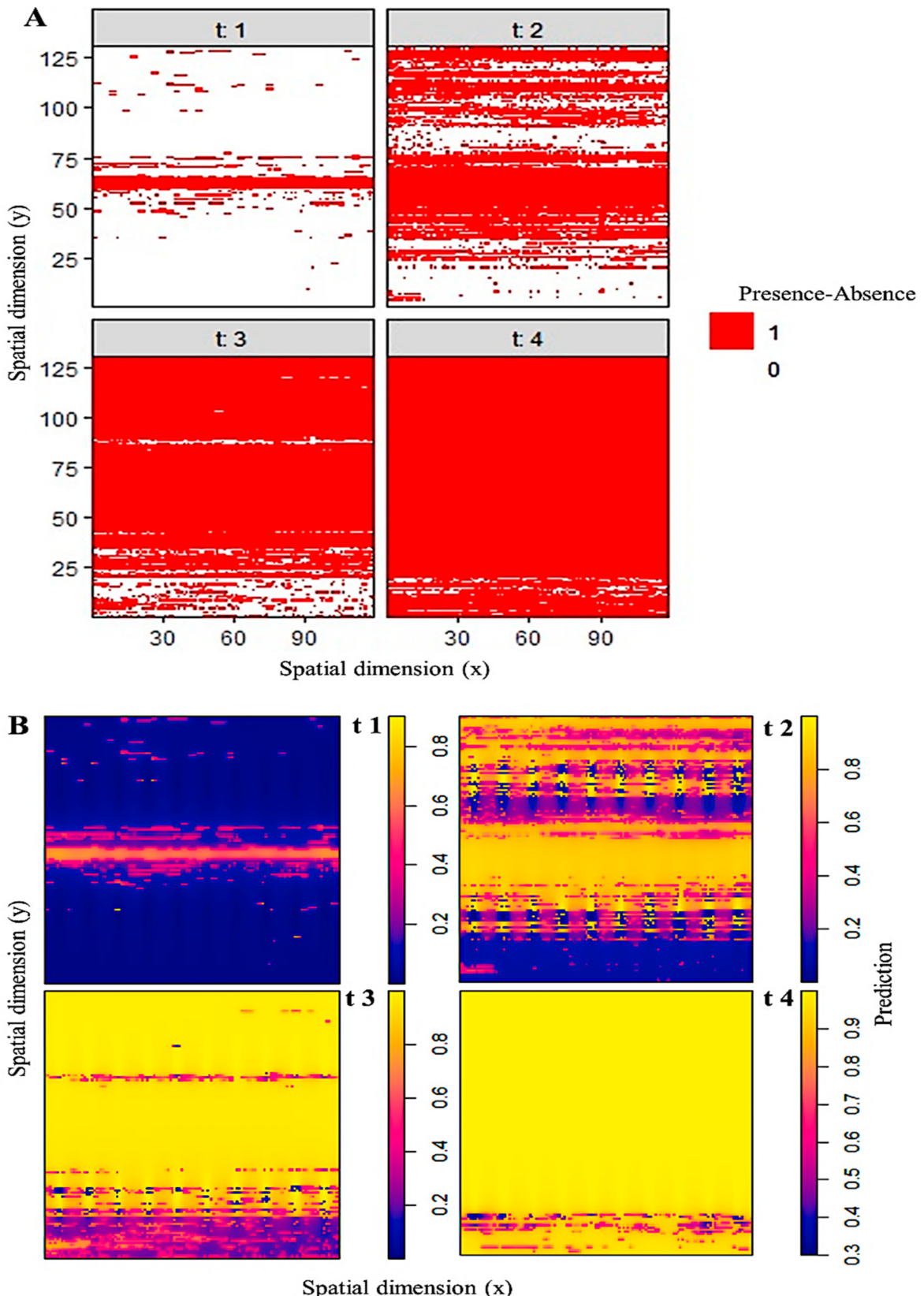

Figure 4. Analysis of spatial distribution of ToBRFV in commercial tomato greenhouses. (A) Sequence observations of presence (1) and absence (0) in space as a function of time based on area patters. (B) Spatial distribution of presence (1) or absence (0) based on point patterns using inverse distance point interpolation $(\mathrm{IDW})(\mathrm{t} 1=$ Week $41, \mathrm{t} 2=$ Week 48, $\mathrm{t} 3=$ Week 50, and $\mathrm{t} 4=$ Week 51). Maps represent spatial dynamics of the disease in Greenhouse 5. 
Using point patterns and IDW interpolation, a disease-intensity map was generated, representing the number of events (presence of ToBRFV) per unit area, which coincided with the previous method, indicating that the analyzed variable presented dependence in the space. In the initial phase of the epidemic (t1), the intensity of the disease was greater in the center of the greenhouse, decreasing towards the ends of the structure. The intensity was also not constant throughout the greenhouse, which indicated that this was not a random event, but a slightly aggregated event, that is, the presence of a ToBRFV case attracted more events to a given area over time (Figure 4B). The type of spatial distribution showed the presence of an inoculum source zone in which the first infections of the pathogen developed. On the other hand, in the rapid-growth stage ( $\mathrm{t} 2)$, the intensity of the disease was greater than that in the initial stage, which represented the presence of a greater number of infected plants due to the production of multiple infection cycles (secondary inoculum source) in most of the greenhouse area (Figure 4B). Lastly, in the deceleration ( $\mathrm{t} 3$ ) and stationary ( $\mathrm{t} 4)$ phases, the maximal intensity of the disease occurred, demonstrating that its dispersal was uniform throughout the greenhouse area at the end of the crop production cycle (Figure 4B).

Lastly, the SADIE index corroborated what was found in the previous methods, indicating that, in the initial stage of the epidemic (t1), there was a source of inoculum (red color) slightly aggregated in the center of the greenhouse, with a high probability of dispersal of the disease towards healthy areas (blue) located towards the ends of the greenhouse. In the rapid- or exponential-growth phase (t2), the amount and distribution of the disease increased, which was represented by the presence of larger red circles, which were distributed in the center and eastern part of the greenhouse. In the deceleration phase ( $\mathrm{t} 3)$, there was greater dispersion and intensity of the disease towards the "eastern" area, with only a small presence in the "western" area, indicating a uniform distribution pattern. Regarding the stationary phase, the greatest proportion of areas were associated with diseased plants and a significant reduction in healthy areas, which resulted in a higher probability of disease occurrence and generalized uniform distribution throughout the greenhouse (Figure 5).
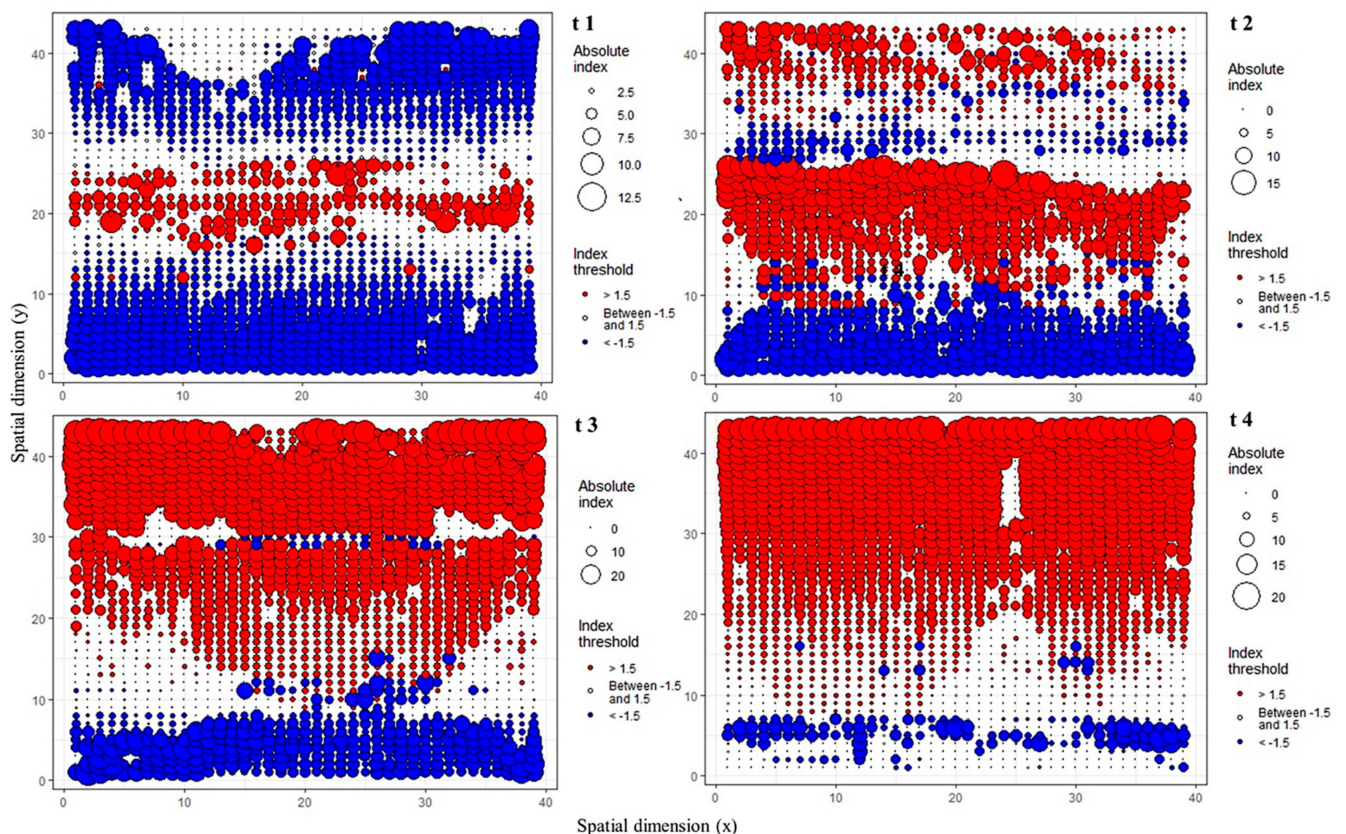

Figure 5. Analysis of spatial distribution of ToBRFV in commercial tomato greenhouses based on Sadie index ( $\mathrm{t} 1=\mathrm{Week}$ $41, \mathrm{t} 2=$ Week $48, \mathrm{t} 3=$ Week 50, and $\mathrm{t} 4=$ Week 51). SADIE index range: values of index range $>1.5$ indicate aggregation of the inoculum source, values of index range $<1.5$ indicate aggregation of healthy plants, and values between -1.5 and 1.5 indicate areas of interception of the two phenomena. Circle size and color (red and blue) indicate the size, intensity, and dimension [36] of the phenomenon (healthy or infected areas). 


\section{Discussion}

The shape of the disease progression curves caused by ToBRFV over time is a typical representation of epidemics that fit logistic population-growth models. These models are the most used in the description of plant epidemics caused by Tobamovirus, where viral particles (infectious units) spread through direct contact between plants [21,40,41]. This type of epidemic is characterized by a very high symmetric absolute rate of change (dy/dt) when $50 \%$ incidence is reached (inflection point) [21,40,41].

The type of graph that represents the logistic models (log-logistic and logistic) is a classic sigmoidal shape, which comprises an initial phase where a slow increase in incidence occurs; then, it increases rapidly in the exponential-growth phase, and lastly slowly approaches the maximal number of infected individuals in the deceleration and stationary phases at the end of the epidemic assessment period [21,40,41], which agrees with what was found in this study with ToBRFV (Figure 6 and Table 3).

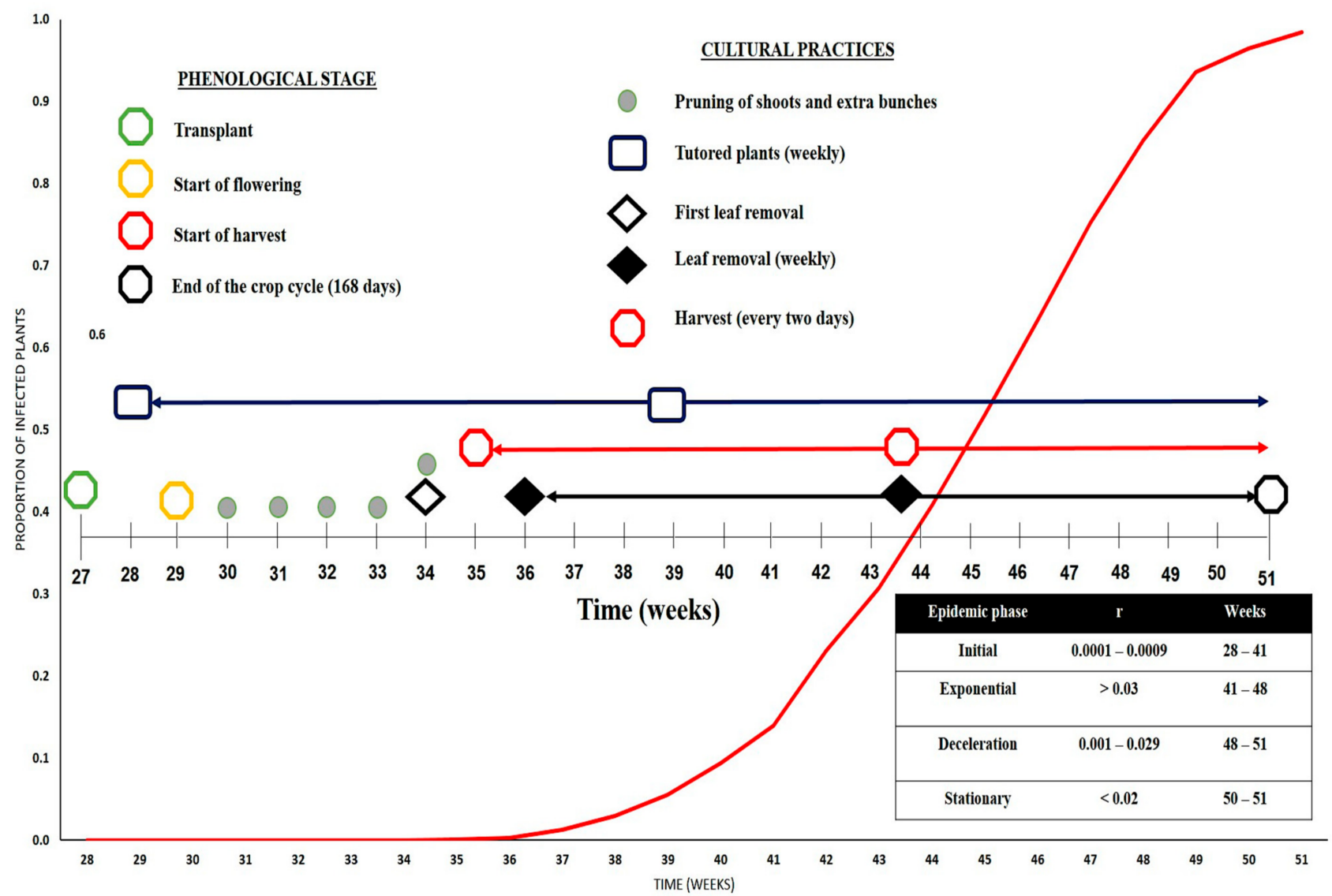

Figure 6. Epidemiological conceptual model of disease progress curve caused by ToBRFV during tomato (Solanum lycopersicum) phenological stages and cultural practices throughout the crop cycle.

Logistic models are best-suited to represent polycyclic diseases, which are characterized by presenting multiple infection cycles during the crop production cycle [21,40,41]. This was evidenced in the rapid-growth phase of this epidemic, where the proportion of diseased plants increased due to the implementation of cultural practices (leaf removal, tutoring, and harvesting) carried out in high-intensity tomato production systems throughout the crop production cycle, thus favoring the mechanical transmission of virus (Figure 6). This polycyclic pathosystem also included the constant production of inoculum mediated by the viral replication processes inside the host cells [42], and the rapid dispersal and subsequent infection of new contacted individuals $[18,21,41]$. The phenomenon of mechanical transmission was explicitly observed from Week 35 onwards, mainly because, from that date, intensive harvesting work began (every other day), favoring viral transmission 
through personnel, and direct contact between diseased and healthy plants $[8,18]$. In addition to harvesting, during weeks 35-51, cultural practices such as tutoring and leaf removal were performed on a weekly basis, further increasing the risk of contagion between plants, thus spreading the virus within the greenhouses (Figure 6).

During weeks 41-48 (exponential phase), there was an increase in the disease-transmission rate, which was directly proportional to the level of incidence; in this period of time, the relative rate of the disease continuously increased, producing the maximal transmission caused by secondary infections within the population of evaluated plants (Figure 6). This phase was characterized by a higher infection rate, which translated into a higher risk of the ToBRFV epidemic occurring over time $[18,21]$.

The ToBRFV polycyclic process showed a relatively mild onset of the disease with a low infection rate during weeks 35-40 due to the presence of only a few diseased plants exhibiting symptoms associated with ToBRFV infection. This means that the main source of inoculum was not infested seed, as the plants at the time of transplanting were 30 days old, by which time they should manifest visual symptoms because the incubation period of ToBRFV corresponds to an interval of 12-18 days after inoculation [11].

It is important to estimate the incubation period within the development of disease epidemics since, from this, the first infections that may be latent within the dynamics of a polycyclic disease such as the one caused by ToBRFV occur after the incubation period. However, secondary infections can overshadow the initial events of the development of this disease, so it is extremely important to know them in order to plan and implement efficient integrated strategies for the management of this disease [21,43].

Although ToBRFV poses a risk of low-frequency transmission by seed, located in the seed coat and endosperm but never in the embryo [5,8], it highly impacts high-intensity production systems [44]. For this reason, it is very likely that the pathogen entered a production unit (greenhouse) through an infected seedling in the nursery, and then the virus was spread by external contamination through field personnel in charge of carrying out the different crop cultural practices in the greenhouses.

Spatial patterns in epidemics are the result of biological dispersal processes and the effect of environmental heterogeneity [45]. In this sense, random distribution in the preinitial epidemiological phase suggests that inoculum origin may come from exogenous infection sources. Additionally, the aggregate patterns found in the last week of the initial and rapid-growth phases of the disease caused by ToBRFV support the type of mechanical transmission that occurs by plant-to-plant contact, which results in the clustering and dispersal in space of diseased plants through the high probability that a plant infects neighboring plants over time; that is, as the incidence of the disease increases, aggregation increases in the same way, favoring the formation of disease dispersal foci in greenhouses $[18,21,46]$. In the last weeks of the deceleration and stationary phases, the found patterns were uniform, as the increase in infection rates in the exponential phase favored the probability that a healthy plant could become diseased due to the reduction in proximity to diseased plants during the final phases of the epidemic [21].

The weak or null aggregation values found in the initial stages of the epidemic (weeks 28-41) indicate that, in the first weeks of disease progression, there was probably a random distribution of ToBRFV-infected plants possibly due to the presence of the virus in a few plants, which initiated the development of the epidemic within the evaluated greenhouses [21].

To date, there are no epidemiological studies on the temporal and spatial dynamics of ToBRFV in commercial tomato greenhouses. However, recently in Sicily, Italy, there was spread of ToBRFV in a 0.05 ha experimental greenhouse over a 9 month period, and an accelerated increase in the spread of infection from $1.45 \%$ to almost $100 \%$ in 8 months was found, with the largest increase (5.8 to 80\%) being in just 3 months (November 2018 to February 2019) [4]. That research showed that the main means of disease transmission was plant-to-plant contact, and that only a few infected plants need to be present for the disease to rapidly spread until it reaches a $100 \%$ incidence value. In contrast, in our study, the 
maximal incidence value (100\%) was reached in half the time (4 months) because, under commercial conditions, crop management is intensified, and cultural practices are carried out more frequently, favoring the mechanical transmission of ToBRFV inside greenhouses.

\section{Conclusions}

The estimation of the statistical parameters for model selection indicated that the logistic models (log-logistic and logistic) were the ones that best fit the data on the temporal progress of the disease caused by ToBRFV in the five evaluated commercial tomato greenhouses. The autocorrelation and spatial-dependence results indicated that, in the initial phase of this epidemic, there was a slightly aggregated spatial pattern with moderate spatial dependence; for the rapid-growth phase, there was a highly aggregated spatial pattern with high spatial dependence; and in the deceleration and stationary phases, there were uniform spatial patterns.

The epidemiological analyses of this pathosystem allowed for us to determine the spatiotemporal dynamics of ToBRFV, which makes it possible to propose and evaluate different integrated strategies for disease management in tomato production systems under greenhouse conditions.

Author Contributions: Conceptualization: L.F.G.-C., J.G.R.-G., R.S.G.-E., Á.R.-A. and J.M.T.-P.; formal analysis: L.F.G.-C. and J.G.R.-G.; investigation, L.F.G.-C. and J.M.T.-P.; writing-original-draft preparation, L.F.G.-C., J.G.R.-G. and R.S.G.-E., Á.R.-A. and J.M.T.-P.; writing-review and editing L.F.G.-C., J.G.R.-G., R.S.G.-E., Á.R.-A. and J.M.T.-P.; supervision, L.F.G.-C., J.G.R.-G., R.S.G.-E., Á.R.-A. and J.M.T.-P. All authors have read and agreed to the published version of the manuscript.

Funding: This research was funded by the Research Center for Food and Development, Culiacán Unit.

Institutional Review Board Statement: Not applicable.

Informed Consent Statement: Not applicable.

Data Availability Statement: Data and R code generated during the current study are available from the corresponding author on reasonable request.

Acknowledgments: We thank Isidro Márquez-Zequera and Luis Alfredo Osuna-García for the technical support.

Conflicts of Interest: The authors declare no conflict of interest.

\section{References}

1. Heuvelink, E. Tomatoes. In Crop Production Science in Horticulture, 2nd ed.; CABI Publishing: Wageningen, The Netherlands, 2018; ISBN 978-1-78064-193-5.

2. FAOSTAT. Food and Agriculture Data. Available online: http://www.fao.org/faostat/en/\#home (accessed on 4 February 2021).

3. Siap Servicio de Información Agroalimentaria y Pesquera: Producción Agrícola. Available online: http://www.gob.mx/siap/ acciones-y-programas/produccion-agricola-33119 (accessed on 11 April 2021).

4. Panno, S.; Caruso, A.G.; Barone, S.; Lo Bosco, G.; Rangel, E.A.; Davino, S. Spread of Tomato Brown Rugose Fruit Virus in Sicily and Evaluation of the Spatiotemporal Dispersion in Experimental Conditions. Agronomy 2020, 10, 834. [CrossRef]

5. Levitzky, N.; Smith, E.; Lachman, O.; Luria, N.; Mizrahi, Y.; Bakelman, H.; Sela, N.; Laskar, O.; Milrot, E.; Dombrovsky, A. The Bumblebee Bombus Terrestris Carries a Primary Inoculum of Tomato Brown Rugose Fruit Virus Contributing to Disease Spread in Tomatoes. PLoS ONE 2019, 14, e0210871. [CrossRef] [PubMed]

6. Ling, K.-S.; Tian, T.; Gurung, S.; Salati, R.; Gilliard, A. First Report of Tomato Brown Rugose Fruit Virus Infecting Greenhouse Tomato in the United States. Plant Dis. 2019, 103, 1439. [CrossRef]

7. Oladokun, J.O.; Halabi, M.H.; Barua, P.; Nath, P.D. Tomato Brown Rugose Fruit Disease: Current Distribution, Knowledge and Future Prospects. Plant Pathol. 2019, 68, 1579-1586. [CrossRef]

8. Davino, S.; Caruso, A.G.; Bertacca, S.; Barone, S.; Panno, S. Tomato Brown Rugose Fruit Virus: Seed Transmission Rate and Efficacy of Different Seed Disinfection Treatments. Plants 2020, 9, 1615. [CrossRef] [PubMed]

9. Aghamohammadi, V.; Rakhshandehroo, F.; Shams-bakhsh, M.; Palukaitis, P. Distribution and Genetic Diversity of Tomato Mosaic Virus Isolates in Iran. J. Plant Pathol. 2013, 95, 339-347.

10. Salem, N.; Mansour, A.; Ciuffo, M.; Falk, B.W.; Turina, M. A New Tobamovirus Infecting Tomato Crops in Jordan. Arch. Virol. 2016, 161, 503-506. [CrossRef] [PubMed] 
11. Luria, N.; Smith, E.; Reingold, V.; Bekelman, I.; Lapidot, M.; Levin, I.; Elad, N.; Tam, Y.; Sela, N.; Abu-Ras, A.; et al. A New Israeli Tobamovirus Isolate Infects Tomato Plants Harboring Tm-22 Resistance Genes. PLoS ONE 2017, 12, e0170429. [CrossRef]

12. Beris, D.; Malandraki, I.; Kektsidou, O.; Theologidis, I.; Vassilakos, N.; Varveri, C. First Report of Tomato Brown Rugose Fruit Virus Infecting Tomato in Greece. Plant Dis. 2020, 104, 2035. [CrossRef]

13. Cambrón-Crisantos, J.M.; Rodríguez-Mendoza, J.; Valencia-Luna, J.B.; Alcasio Rangel, S.; de Jesús García-Ávila, C.; López-Buenfil, J.A.; Ochoa-Martínez, D.L.; Cambrón-Crisantos, J.M.; Rodríguez-Mendoza, J.; Valencia-Luna, J.B.; et al. First Report of Tomato Brown Rugose Fruit Virus (ToBRFV) in Michoacan, Mexico. Rev. Mex. Fitopatol. 2019, 37, 185-192. [CrossRef]

14. Camacho-Beltrán, E.; Pérez-Villarreal, A.; Leyva-López, N.E.; Rodríguez-Negrete, E.A.; Ceniceros-Ojeda, E.A.; Méndez-Lozano, J. Occurrence of Tomato Brown Rugose Fruit Virus Infecting Tomato Crops in Mexico. Plant Dis. 2019, 103, 1440. [CrossRef]

15. Koh, S.H.; Li, H.; Sivasithamparam, K.; Admiraal, R.; Jones, M.G.K.; Wylie, S.J. Low Root-to-Root Transmission of a Tobamovirus, Yellow Tailflower Mild Mottle Virus, and Resilience of Its Virions. Plant Pathol. 2018, 67, 651-659. [CrossRef]

16. Jones, R.A.C. Trends in Plant Virus Epidemiology: Opportunities from New or Improved Technologies. Virus Res. 2014, 186, 3-19. [CrossRef]

17. Jones, R.A.C. Plant Virus Ecology and Epidemiology: Historical Perspectives, Recent Progress and Future Prospects. Ann. Appl. Biol. 2014, 164, 320-347. [CrossRef]

18. Jeger, M.J.; Madden, L.V.; van den Bosch, F. Plant Virus Epidemiology: Applications and Prospects for Mathematical Modeling and Analysis to Improve Understanding and Disease Control. Plant Dis. 2018, 102, 837-854. [CrossRef]

19. Ojiambo, P.S.; Yuen, J.; van den Bosch, F.; Madden, L.V. Epidemiology: Past, Present, and Future Impacts on Understanding Disease Dynamics and Improving Plant Disease Management-A Summary of Focus Issue Articles. Phytopathology 2017, 107, 1092-1094. [CrossRef]

20. Rodríguez-Mendoza, J.; de Jesús García-Ávila, C.; López-Buenfil, J.A.; Araujo-Ruiz, K.; Quezada-Salinas, A.; Cambrón-Crisantos, J.M.; Ochoa-Martínez, D.L. Identification of Tomato Brown Rugose Fruit Virus by RT-PCR from a Coding Region of Replicase (RdRP). Rev. Mex. Fitopatol. 2019, 37, 345-356. [CrossRef]

21. Madden, L.V.; Hughes, G.; van den Bosch, F. The Study of Plant Disease Epidemics; American Phytopathological Society (APS Press): St. Paul, MN, USA, 2007; ISBN 978-0-89054-505-8.

22. Gupta, R.C.; Akman, O.; Lvin, S. A Study of Log-Logistic Model in Survival Analysis. Biom. J. 1999, 41, 431-443. [CrossRef]

23. Pennypacker, S.; Knoble, H.D.; Antle, C.; Madden, L. A Flexible Model for Studying Plant Disease Progression. Phytopathology 1980, 70, 232-235. [CrossRef]

24. R Development Core Team. R: The R Project for Statistical Computing. Available online: https://www.r-project.org/ (accessed on 1 January 2021).

25. Wood, S. Mgcv: Mixed GAM Computation Vehicle with Automatic Smoothness Estimation. 2019. Available online: https: //mran.revolutionanalytics.com/snapshot/2019-04-07/web/packages/mgcv/mgcv.pdf (accessed on 1 January 2021).

26. Hunt, T. ModelMetrics: Rapid Calculation of Model Metrics. 2020. Available online: https://cran.r-project.org/web/packages/ ModelMetrics/readme/README.html (accessed on 1 January 2021).

27. Ritz, C.; Strebig, J.C. Drc: Analysis of Dose-Response Curves. 2016. Available online: https://cran.r-project.org/web/packages/ drc/drc.pdf (accessed on 1 January 2021).

28. Moran, P.A.P. The Interpretation of Statistical Maps. J. R. Stat. Soc. Ser. B 1948, 10, 243-251. [CrossRef]

29. Fisher, R.A. Statistical Methods for Research Workers. In Breakthroughs in Statistics: Methodology and Distribution; Springer Series in Statistics; Kotz, S., Johnson, N.L., Eds.; Springer: New York, NY, USA, 1992; pp. 66-70. ISBN 978-1-4612-4380-9.

30. Lloyd, M. Mean Crowding. J. Anim. Ecol. 1967, 36, 1-30. [CrossRef]

31. Cambardella, C.A.; Moorman, T.B.; Parkin, T.B.; Karlen, D.L.; Novak, J.M.; Turco, R.F.; Konopka, A.E. Field-Scale Variability of Soil Properties in Central Iowa Soils. Soil Sci. Soc. Am. J. 1994, 58, 1501-1511. [CrossRef]

32. Watson, D.; Phillip, G. A Refinement of Inverse Distance Weighted Interpolation. Geoprocessing 1985, 2, 315-327.

33. Perry, J.N. Spatial Analysis by Distance Indices. J. Anim. Ecol. 1995, 64, 303-314. [CrossRef]

34. Dáder, B.; Moreno, A.; Viñuela, E.; Fereres, A. Spatio-Temporal Dynamics of Viruses Are Differentially Affected by Parasitoids Depending on the Mode of Transmission. Viruses 2012, 4, 3069-3089. [CrossRef] [PubMed]

35. Li, B.; Madden, L.V.; Xu, X. Spatial Analysis by Distance Indices: An Alternative Local Clustering Index for Studying Spatial Patterns. Methods Ecol. Evol. 2012, 3, 368-377. [CrossRef]

36. Perry, J.N.; Winder, L.; Holland, J.M.; Alston, R.D. Red-Blue Plots for Detecting Clusters in Count Data. Ecol. Lett. 1999, 2, 106-113. [CrossRef]

37. Ribeiro, P.J.; Diggle, P.J. GeoR: Analysis of Geostatistical Data. 2018. Available online: https://cran.r-project.org/package=geoR (accessed on 1 January 2021).

38. Gigot, C. Epiphy: Analysis of Plant Disease Epidemics. 2018. Available online: https://cloud.r-project.org/web/packages/ epiphy/index.html (accessed on 1 January 2021).

39. Akima, H.; Gebhardt, A.; Petzold, T.; Maechler, M. Akima: Interpolation of Irregularly and Regularly Spaced Data. 2020. Available online: https: / / cran.r-project.org/web/packages/akima/index.html (accessed on 1 January 2021).

40. Nutter, F.W. Quantifying the Temporal Dynamics of Plant Virus Epidemics: A Review. Crop. Prot. 1997, 16, 603-618. [CrossRef]

41. Cooke, B.M.; Jones, D.G.; Kaye, B. (Eds.) The Epidemiology of Plant Diseases, 2nd ed.; Springer: Dordrecht, The Netherlands, 2006; ISBN 978-1-4020-4579-0. 
42. Smith, E.; Dombrovsky, A. Aspects in Tobamovirus Management in Intensive Agriculture. Plant Dis. Curr. Threat. Manag. Trends 2019. [CrossRef]

43. Favara, G.M.; Bampi, D.; Molina, J.P.E.; Rezende, J.A.M. Kinetics of Systemic Invasion and Latent and Incubation Periods of Tomato Severe Rugose Virus and Tomato Chlorosis Virus in Single and Co-Infections in Tomato Plants. Phytopathology 2019, 109, 480-487. [CrossRef]

44. Tatineni, S.; Stewart, L.R.; Sanfaçon, H.; Wang, X.; Navas-Castillo, J.; Hajimorad, M.R. Fundamental Aspects of Plant Viruses-An Overview on Focus Issue Articles. Phytopathology 2020, 110, 6-9. [CrossRef]

45. Willocquet, L.; Savary, S. An Epidemiological Simulation Model with Three Scales of Spatial Hierarchy. Phytopathology 2004, 94, 883-891. [CrossRef]

46. Gosme, M.; Lucas, P. Cascade: An Epidemiological Model to Simulate Disease Spread and Aggregation across Multiple Scales in a Spatial Hierarchy. Phytopathology 2009, 99, 823-832. [CrossRef] 